\title{
Asset Management of Linear Civil Infrastructure - Through the Lens of a Changing Climate
}

\author{
Shawn Kenny* \\ Department of Civil and Environmental Engineering, Carleton University, Ottawa, Canada
}

*Corresponding author: Shawn Kenny, Department of Civil and Environmental

Engineering, Carleton University, Ottawa, Canada, Email: shawn.kenny@carleton.ca

Received Date: April 12, 2019

Published Date: April 26, 2019

\section{Background}

Core linear civil infrastructure systems (e.g. roads, bridges, buried utilities and pipelines) are critical elements of society that meet our functional needs, sustain economic growth and development, and support our current standard of living through the transport of people, services, goods, water and energy. In Canada, approximately $60 \%$ of this core infrastructure is owned and maintained by local municipalities with a total asset value of \$1.1 trillion [1]. Throughout much of North America, a significant proportion of this core infrastructure was built in the 1950's and 1960's. Although investments in public infrastructure have continued, these assets have experienced stress from deterioration due to ageing and weathering effects, deferred maintenance, and increased utilization. From the Canadian perspective, the variation in core infrastructure age over time, as a composite asset average, has fluctuated between 14 years and 18 years over the past 5 decades [2]. Approximately one-third of the existing Canadian infrastructure network ranks between "fair" and "very poor", which is associated with limited funding, deferred maintenance and increased utilization [1]. This "investment gap" has pushed these assets toward $79 \%$ of used service life. The infrastructure gap has been estimated to be $\$ 60$ billion (2012\$) in Ontario, $\$ 145$ billion (2013\$) across Canada and exceeding \$2 trillion (2016\$) in the United States with a projected loss in gross domestic product of $\$ 3.9$ trillion through to 2025 [1,3-5]. The annual deficit can be an order of magnitude greater than the annual budget where the reactive costs can be up to 10 times the preventative costs.

Stakeholders (i.e. government, industry, and society) have recognized the interdependent relationship between the investment gap, deteriorating performance of core infrastructure and implications for not achieving operational goals and targeted service levels. Establishing an informed and effective decisionmaking framework is critical for the prioritization of needs and actions, as well as the allocation of human and capital resources. To address these issues, municipalities should have an integrated asset management plan as part of their toolbox. Asset management can be defined as coordinated activities, conducted across an organization and in partnership with stakeholders, to realize value from assets through a deliberate approach with respect to planning, implementation and execution. The value realization must balance cost, benefits, risks, opportunities, performance and service level targets. The principles of infrastructure asset management are well established [6-14]. In addition, professional organizations have advanced supporting best practices and tools [6,15-18]. An integrated asset management framework and the relationships across stakeholders, for municipalities, is illustrated in Figure 1. The integration is multifaceted where the stakeholders are coordinated within their respective levels (e.g. operations team) and management teams) but also engaged with other stakeholder interfaces (e.g. strategic/tactical alignment). For smaller population centers $(<100,000)$, approximately $91 \%$ of municipalities across Canada [1] and 95\% across Ontario have in-place asset management plans (Figure 1).

\section{Climate Change Effects and Considerations}

Local climate change effects (e.g. erratic or cyclic temperature variation) add another layer of complexity that shape and impact how we manage assets, and address or experience infrastructure performance (e.g. increased level of damage such as rutting or potholes). The frequency, scale and intensity of climate change related hazards (e.g. flooding, geohazards) are expected to increase, with more adverse outcomes, where current load events may exceed the original design basis $[19,20]$. From the Canadian perspective, northern regions have been witness to accelerated infrastructure deterioration, landscape transformations and disturbed ecosystems due to adverse climate change effects on 
permafrost, which is approximately 50\% of Canada's landmass [19-26]. Reliance on the historical climate record and current engineering practice will most likely lead to an increased exposure and vulnerability of infrastructure. This may have negative effects on asset performance and integrity that could result in economic loss, personal injury and loss of life. There is empirical evidence to support these hypothetical scenarios. For example, the cumulative payout ( $\$ 3.3$ billion), since the 2009-10 fiscal year, for the Canadian National Disaster Financial Assistance Arrangements Program exceeds the cumulative payout (\$2.4 billion) for the previous 39 years. The detrimental effects of a changing climate are reinforced by data from the Insurance Bureau of Canada for catastrophic disaster payout, which is defined as payouts greater than $\$ 25$ million for property and casualty insurance [4,27]. Over the 5-year period from 2010 to 2015, the total catastrophic loss has increased by an order of magnitude to $\$ 10.6$ billion (2017\$) in comparison with the 5-year period from 1983 to 1988 . Moreover, the future cost for Canadians due to climate change effects across multiple sectors (e.g. health, transportation, energy, natural resources, ecosystems) is estimated to be $\$ 5$ billion per year in 2020 and may reach $\$ 43$ billion per year by 2050 [28].

Confronted with the realities of a changing climate, over the past two decades there has been a greater concerted engagement by stakeholders to advance foundational supporting elements, across a broad landscape, that includes outreach and training, guidance documents, codes of practice and critical reviews as they relate to engineering practices, asset management and policy development [16,19,20,29-41]. However, a formalized framework (e.g. recommended practice, guidance document) or prescriptive requirement (e.g. code, standard, regulation) for the direct integration of climate change considerations within asset management plans, for core municipal infrastructure, has not been established $[4,5,29]$. This is reflected in the Ontario landscape where the majority of rural communities $(77 \%$ of 120 respondents) have not considered climate change impacts within the development of asset management plans [4]. The lack of inplace sustainability plans (74\% stated either No or Future Study for the 120 responses) and public engagement (66\% stated No for 145 responses) may have been contributing factors. This is mirrored at the national scale where only $19 \%$ of municipalities have integrated climate change considerations within internal mechanisms; such as policies and adaptation practices [1].

\section{Outlook}

Current engineering practice used to evaluate the impact of hazards on the performance and integrity of linear civil infrastructure systems have inherent deficiencies and uncertainties. These limitations create barriers to making informed decisions that ultimately impact the development of effective, sustainable and practical engineering practices to address the challenges being faced [42]. Guidance and direction for municipalities to incorporate climate change considerations and adaptation practices within municipal asset management plans is in the early stages of development. Comprehensive stakeholder engagement (i.e. inform, communicate and listen) across and within the layered network (Figure 1), and integration of the technical (i.e. engineering, financial, budgetary, service levels), governance (i.e. strategy, vision, expectations) and regulatory (i.e. policies, codes, standards) domains is required. In view of the complex interdependent relationships associated with problem scale across administrative jurisdictions (e.g. federal, regional and local governments), scope (e.g. infrastructure asset mix, climate change stressor, service level targets), resources (e.g. technical capabilities, staff, financial) and requirements (e.g. local policies and plans, regulations), then the development of a generalized, flexible framework is probably a preferred approach. This adaptable framework can be tailored to address specific, municipal-centric needs and goals while accounting for the local capabilities, resources, enablers and constraints.

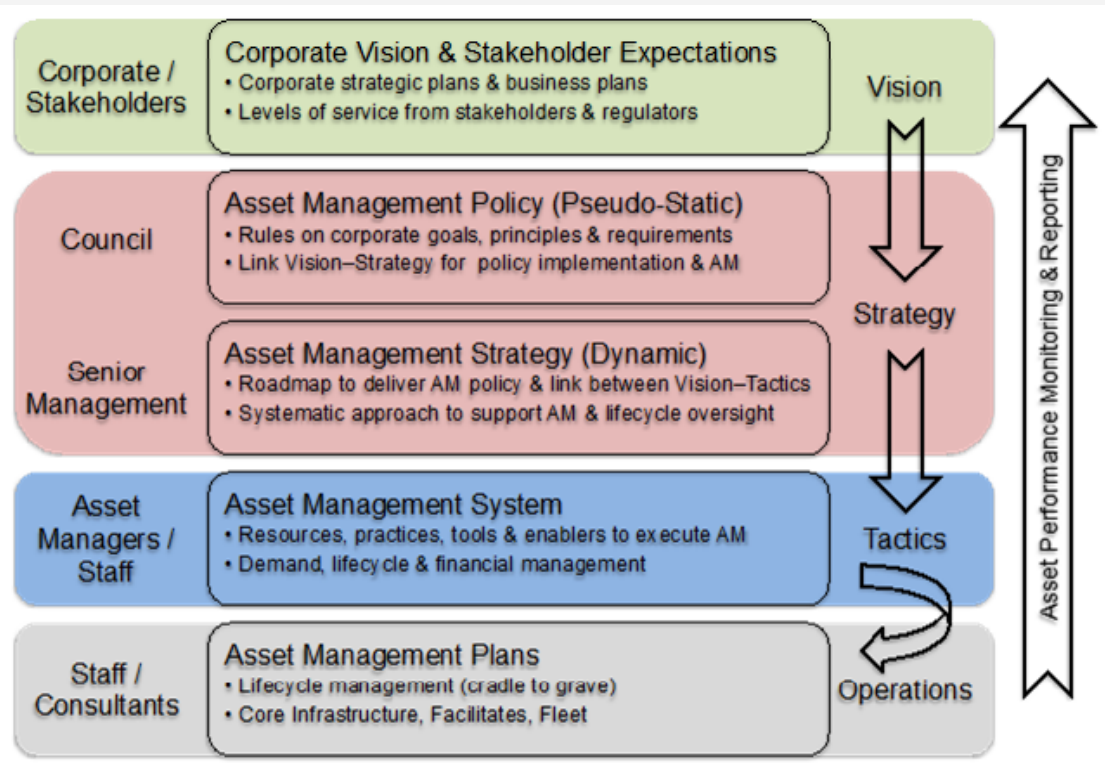

Figure 1: Integrated asset management framework for municipalities. 
A possible integrated approach, which accounts for the interdependent relationships among climate change assessment, risk management and asset management practices, is schematically illustrated in Figure 2. The major integrated activities within the framework, including asset management, risk management and climate change assessment, are represented by shaded rectangular elements. The envisioned framework would integrate best practices with respect to climate change projection and effects integration $[20,30,43]$, infrastructure vulnerability assessment $[33,44,45]$, climate and asset risk management [46-48] and adaptation practices $[29,41]$ within asset management framework [6-10,49] (Figure 2).

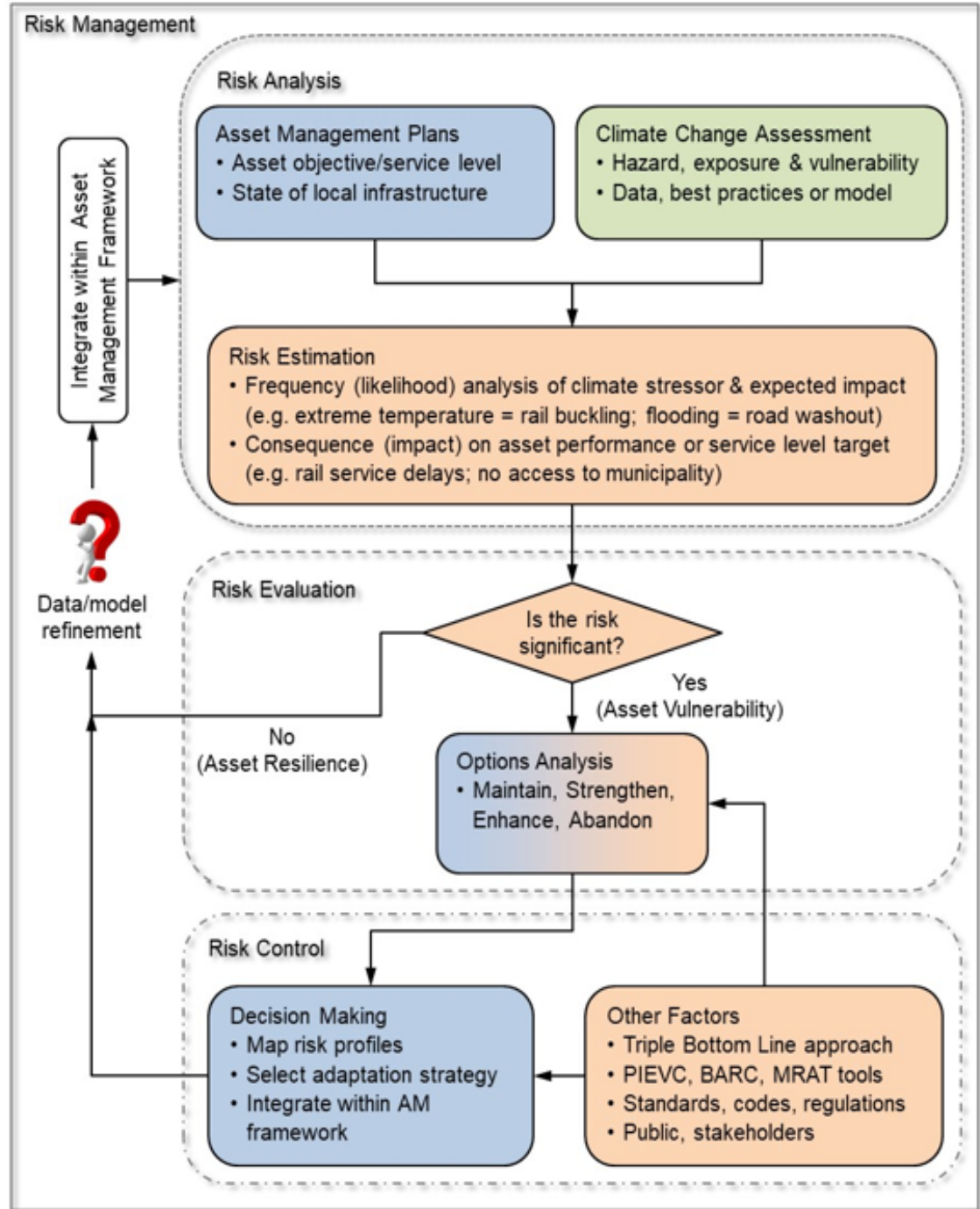

\section{Legend for Integrated Activities}

Asset Management

Risk Management

Climate Change Assessment

Figure 2: Conceptual integration of asset vulnerability assessment, risk management and adaptation practices within asset management framework for core infrastructure.

The prediction of future climate change effects on core infrastructure presents significant challenges due to the complexity of climate change projection models with respect to procedures and verification basis, local, regional and global scale effects, number of interdependent variables, model sensitivity to variation in the governing parameters and uncertainty in the underlying datasets and modelling procedures [50]. For example, depending on the scenario and pathways examined, the climate change projections for Ontario, using a 1971-2000 year baseline for the period 20112040 , includes an increased mean temperature change of $+2.2{ }^{\circ} \mathrm{C}$ and mean precipitation change of $+25.6 \mathrm{~mm}$. Across the province of Ontario, however, the range of these climate change effects may be $+1.6{ }^{\circ} \mathrm{C}$ to $+3.4{ }^{\circ} \mathrm{C}$ and $-125 \mathrm{~mm}$ to $+189 \mathrm{~mm}$ [51]. From the perspective of infrastructure asset management, the climate change risk assessment must evaluate the variability and uncertainty associated with climate change event prediction, climate hazard characteristics (i.e. type, duration, magnitude and intensity), and the infrastructure exposure and vulnerability (Figure 3). A concept related to climate change assessment, which was also presented in Figure 2, is asset resilience based on the system ability to meet operational (i.e. serviceability) performance requirements in response to challenges from climate hazards and adverse events (Figure 3). 


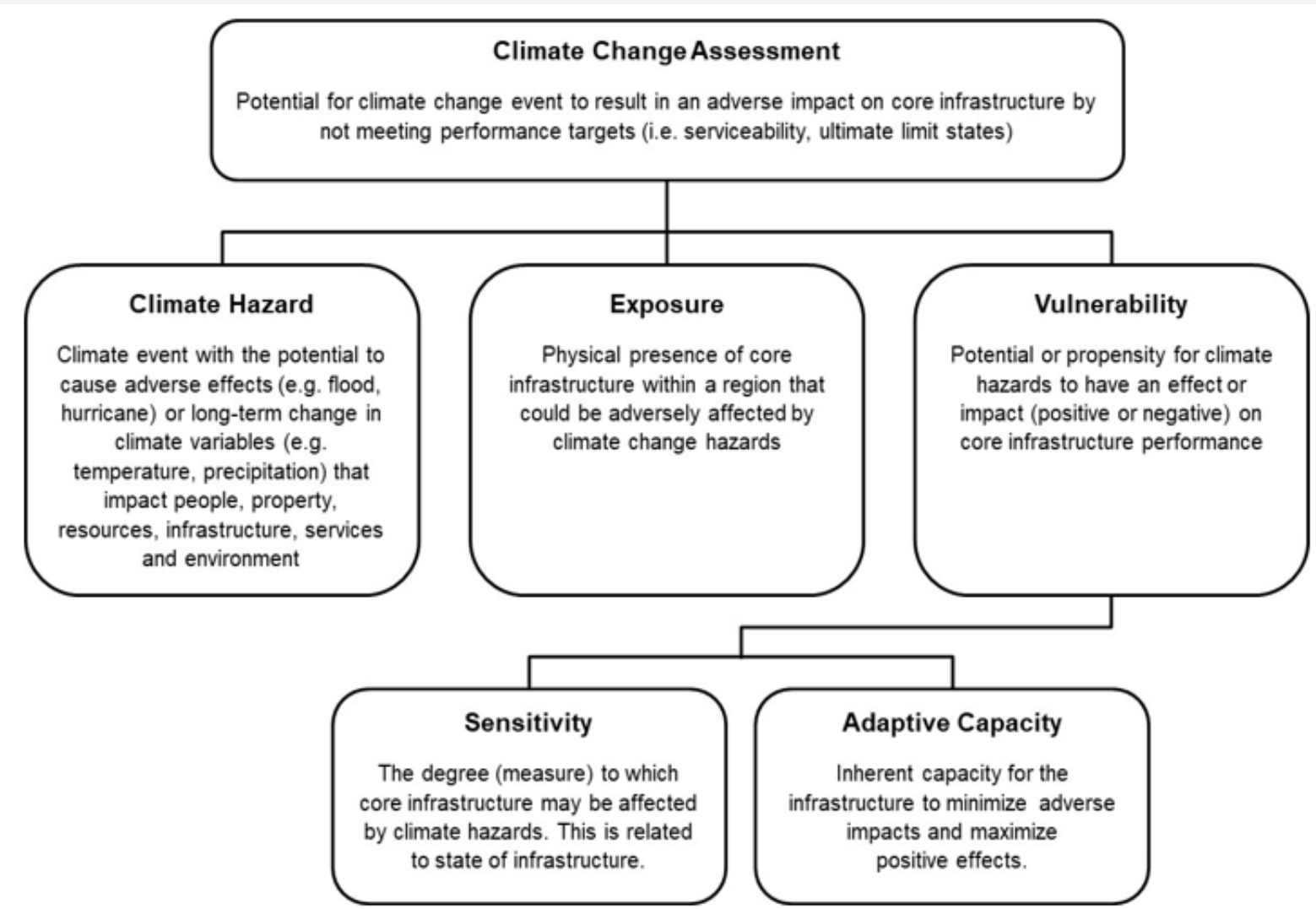

Figure 3: Elements of climate change assessment (after IISD, 2013).
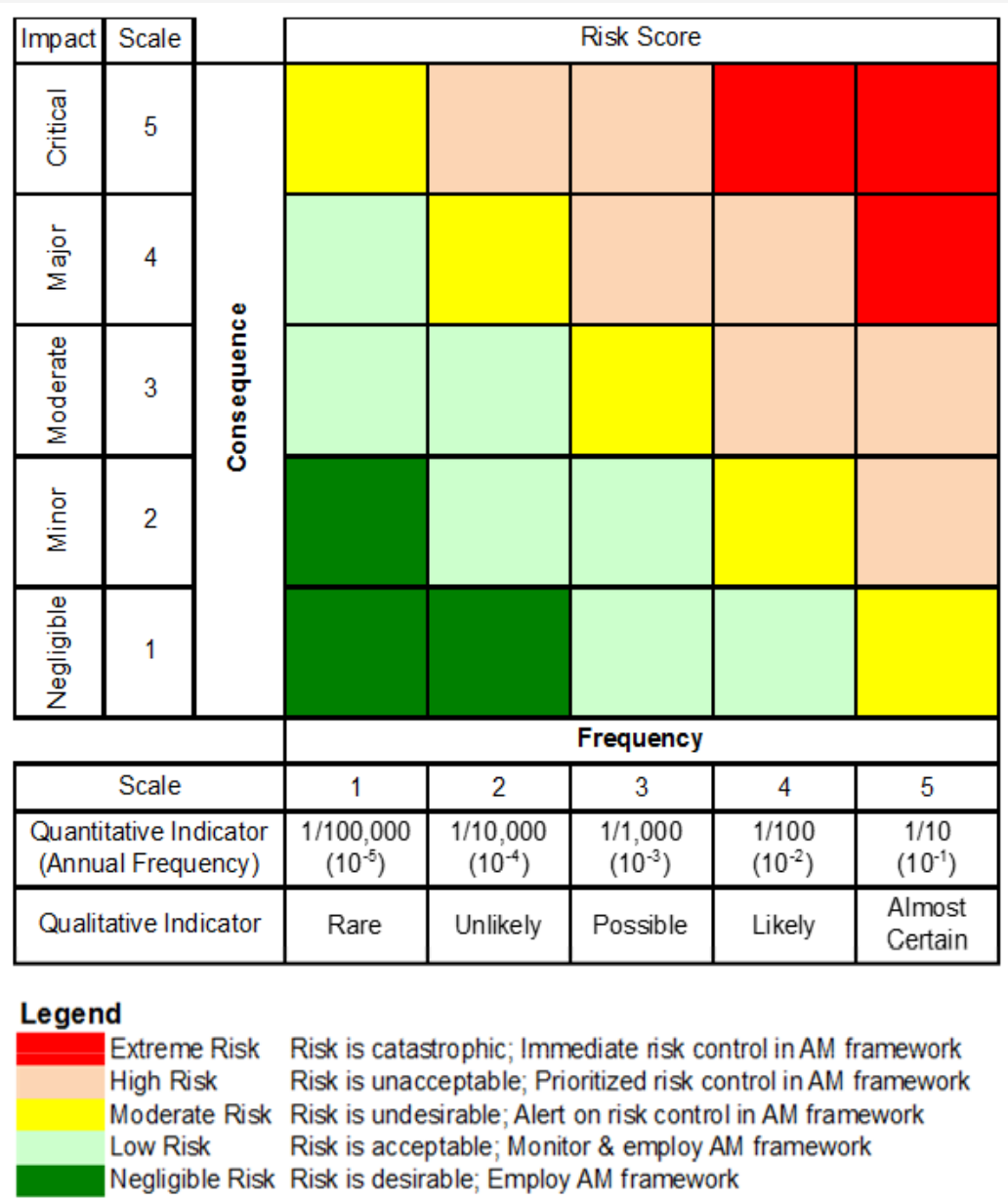

Figure 4: Risk analysis matrix approach for climate hazards impacting asset performance. 
The risk management process would integrate standardized or accepted glossary, norms and practices [47]. The risk analysis could adopt matrix approach that estimates the frequency (likelihood) of a climate hazard (stressor) and associated expected resulting condition in relation to the expected consequence (impact) on the asset performance or service level target. This approach is schematically illustrated in Figure 4 with the semi-quantitative risk estimate based on the product of event annual frequency of the climate hazard with the consequence on the asset performance or service target level. Other studies have used similar matrix approaches to estimate the risk of climate change hazards on the resilience or vulnerability of infrastructure [30,33,45,46,48,52,53] (Figure 4).

Clearly, the process for advancing a comprehensive integrated asset management framework that accounts for climate change considerations embodies a complex, multi-disciplinary relationship among climate science, finance, engineering, risk, governance, policy and regulatory domains. Through engaged stakeholders, forward looking guidance and enabling resources (e.g. tools, standards, best practices) will evolve whereby a comprehensive, municipal-centric asset management framework that integrates considerations of climate change with other key attributes (e.g. risk, data needs, resources, technologies, financial plan, stakeholder engagement) will be advanced.

\section{Acknowledgement}

The authors would like to acknowledge the Ontario Ministry of Agriculture, Food and Rural Affairs (OMAFRA) for the funding to support this study through the New Directions Research Program. The authors would also like to thank the feedback and contributions from the Steering Committee including Cohen Langerak (OMAFRA), Melanie Kawalec (City of Peterborough), Sheridan Graham (Peterborough County) and Dave Clifford (Township of DouroDummer).

\section{References}

1. CIRC (2016) Informing the Future: The Canadian Infrastructure Report Card p.164.

2. Gagnon M, Gaudreault V, Overton D (2008) Age of Public Infrastructure: A Provincial Perspective. Statistics Canada Catalgue p.27.

3. ASCE (2016) Failure to Act: Closing the Infrastructure Investment Gap for America's Economic Future, American Society of Civil Engineers p.32.

4. Kenny S, Dupré K, McEvoy A (2018) Climate change considerations within the asset management of core infrastructure for rural Ontario municipalities - An initial assessment. Proc., CSCE-GC126: p.10.

5. Kenny S, Dupré K, McEvoy A (2019) Asset management of rural Ontario core infrastructure - Drivers and barriers associated with climate change considerations. Proc., CSCE Conference (under review).

6. IAM (2015) Asset Management: An Anatomy. The Institute of Asset Management. P.84.

7. IIMM (2015a) International Infrastructure Management Manual. (5 Edn) Institute of Public Works Engineering Australasia (IPWEA)

8. IIMM (2015b) IIMM Supplement 2015: Meeting ISO 55001 Requirements for Asset Management. Institute of Public Works Engineering Australasia (IPWEA) p.32.
9. ISO 55000 (2014) Asset Management - Overview, Principles and Terminology. ISO 55000, International Organization for Standardization, Geneva, Switzerland, p.19.

10.ISO 55001 (2014) Asset Management - Management System: Requirements. ISO 55001, International Organization for Standardization, Geneva, Switzerland, p.14.

11.ISO 55002 (2014) Asset Management - Management Systems: Guidelines for the Application of ISO 55001. ISO 55002, International Organization for Standardization, Geneva, Switzerland, p.19.

12. Waugh R (2015) Infrastructure asset management - Making everything as simple as possible. Proc., IFME (International Federation of Municipal Engineering) World Congress, Rotorua, New Zealand, p.10.

13. Waugh R (2012) Study on the development of asset management appropriate practice and maturity assessments in Australasia. Proc., IFME (International Federation of Municipal Engineering) World Congress, Helsinki, Finland p.15.

14. Waugh R (2005) NZ asset management - Review and lessons learnt. Proc., IPWEA (Institute of Public Works Engineering Australasia), Adelaide, Australia, p.8.

15. CNAM (2016) Canadian Network of Asset Managers.

16. FCM (2005) Decision Making and Investment Planning: Managing Infrastructure Assets. Federation of Canadian Municipalities, 40p.

17. MFOA (2016) Municipal Finance Officers' Association.

18. OGRA (2016) Ontario Good Roads Association.

19. IISD (2013) Climate Change Adaptation and Canadian Infrastructure: A Review of the Literature. International Institute for Sustainable Development p.35.

20. Transport Canada (2017) Climate Risks and Adaptation Practices for the Canadian Transportation Sector 2016. Editors K Palko, DS Lemmen, p.309.

21. Burn CR, Moore JL, Brendan O’Neill, Hayley DW (2015) Permafrost characterization of the Dempster Highway, Yukon and Northwest Territories. Paper 705, Proc., 68th CGS p.8.

22. Calmels F, Louis-Philippe R, Cyrielle L, Maude P, et al. (2015) Vulnerability of the North Alaska Highway to Permafrost Thaw: A Field Guide and Data Synthesis. Northern Climate ExChange, Yukon Research Centre, Yukon College p.121.

23. Heginbottom JA (1995) Canada - Permafrost, in: National Atlas of Canada, 5th Edition, National Atlas Information Service, Natural Resources Canada, MCR 4177.

24. O'Neill HB, Burn CR, Kokelj SV (2015) Field measurements of permafrost conditions beside the Dempster Highway embankment, Peel Plateau, NWT Proc., GeoQuébec, CGS, p.7.

25. PTP (2011) Pan-Territorial Adaptation Strategy: Moving Forward on Climate Change Adaptation in Canada's North. Governments of the Northwest Territories, Nunavut and Yukon p.32.

26. PTP (2014) Pan-Territorial Permafrost Workshop: Summary Report. Prepared by the Government of the Northwest Territories, Government of Nunavut and Government of Yukon p.86.

27. IBC (2016) Facts of the Property and Casualty Insurance Industry in Canada 2016. Insurance Bureau of Canada p.66.

28. NRT (2011) Paying the Price: The Economic Impacts of Climate Change for Canada. National Round Table on the Environment and the Economy p.168.

29. AMEC (2017) National Infrastructure and Buildings Climate Change Adaptation State of Play Report. Prepared for Natural Resources Canada, Prepared by Amec Foster Wheeler and Credit Valley Conservation, p.78.

30.APEGBC (2017) Developing Climate Change-Resilient Design for Highway Infrastructure in British Columbia (Interim) Professional Engineers and Geoscientists of British Columbia p.101. 
31. Carnagie Mellon (2017) Masters Concentration in Climate Change Adaptation.

32. CBCL (2012) Managing Municipal Infrastructure in a Changing Climate. Municipalities Newfoundland and Labrador p.41.

33. Engineers Canada (2016) PIEVC Engineering Protocol: Infrastructure Vulnerability Assessment and Adaptation to a Changing Climate: Principles and Guidelines. Version PG-10.1, Engineers Canada p.54.

34. Engineers Canada (2014) National Guideline on Principles of Climate Change Adaptation for Professional Engineers. Engineers Canada p.18.

35. Higgins A (2011) Adaptive Infrastructure Regulation: Designing for Climate Change. M.Law UBC, p.181.

36. MOE (2009) Adapting to Climate Change in Ontario: Towards the Design and Implementation of a Strategy and Action Plan. Prepared by the Expert Panel on Climate Change and Adaptation, Minister of the Environment and Climate Change p.96.

37. MOECC (2015) Ontario's Climate Change Strategy. Minister of the Environment and Climate Change, p.40.

38. NRCan (2014) Canada in a Changing Climate: Sector Perspectives on Impacts and Adaptation. Editors FJ Warren, DS Lemmen, Natural Resources Canada p.286.

39. PIEVC (2008) Adapting to Climate Change: Canada's First National Engineering Vulnerability Assessment of Public Infrastructure P.76.

40. USACE (2014) Climate Change Adaptation Plan. U.S. Army Corps of Engineers p.53.

41. WFEO (2015) Model Code of Practice: Principles of Climate Change Adaptation for Engineers. World Federation of Engineering Organizations p.35.

42. AGO (2015) Annual Report 2015. Office of the Auditor General of Ontario, ISSN 1911-7078 (Online), p.776.

43. AASHTO (2015) Integrating Extreme Weather into Transportation Asset Management Plans. American Association of State Highway and Transportation Officials (AASHTO), Standing Committee on the Environment, NCHRP Project 25-25, Task (94): p.53.
44. Félio G (2015) Vulnerability and adaptation of transportation infrastructure to climate change. Transportation Association of Canada Conference, Canada, p.19.

45. Lapp D (2016) Infrastructure and Climate Change: Assessing Risk and Vulnerabilities to Inform Professional Practice. AIM Network Asset Management Conference, AIM Workshop: On the Road to Asset Management, 33 Slides.

46. Black RA, Bruce JP, Egener IDM (2014) Canadian Climate Change Risk Assessment Guide: A Strategic Overview of Climate Risks and Their Impact on Organizations. Summit Enterprises International Inc. p.31.

47. ISO 31000 (2009) Risk Management: Principles and Guidelines. ISO 31000, International Organization for Standardization, Geneva, Switzerland, p.24.

48. Praill S (2016) Municipal Risk Assessment Tool (MRAT) Proc., CSCENDM-561, p.6.

49. MOI (2017) Proposed Municipal Asset Management Planning Regulation Update. Maureen Johnson, Manager, Municipal Infrastructure Policy, Ontario Ministry of Infrastructure, Asset Management Symposium, Municipal Finance Officers' Association of Ontario (MFOA).

50. IPCC (2014) Climate Change 2014: Synthesis Report. Contribution of Working Groups I, II and III to the 5th Assessment Report of the Intergovernmental Panel on Climate Change [Core Writing Team, R.K. Pachauri and L.A. Meyer (eds.)]. IPCC, Geneva, Switzerland, p.151.

51. McDermid J, Fera S, Hogg A (2015) Climate Change Projections for Ontario: An Updated Synthesis for Policymakers and Planners. Ministry of Natural Resources and Forestry, Government of Ontario p.40.

52. ICLEI (2010) Changing Climate, Changing Communities: Guide and Workbook for Municipal Climate Adaptation. ICLEI Canada, p.79.

53. ICLR (2012) A Plan Forward: Building Practices to Increase the Resilience of Homes to Severe Weather. Institute for Catastrophic Loss Reduction p.24. 